\title{
Ensino de funções nas ciências agrárias: uma prática contextualizada nos cursos de agronomia e zootecnia
}

\section{The teaching of functions in agrarian sciences: a contextualized practice in agronomy courses and zootechny}

\author{
1 Luciana Boemer Cesar Pereira lucesarboemerpg@yahoo.com.br \\ 1 Guataçara dos Santos Junior
}

\section{RESUMO}

Este texto objetiva compartilhar uma experiência de ensino de funções matemáticas na área Ciências Agrária, por meio de uma prática contextualizada em sala de aula, nos cursos de Agronomia e Zootecnia da UTFPR (Universidade Tecnológica Federal do Paraná) Campus Dois Vizinhos-Paraná-Brasil. A experiência de ensino foi realizada com 3 (três) turmas de Agronomia (2013, 2014 e 2016) e 3 (três) turmas de Zootecnia (2013, 2014 e 2015). Com esta experiência de ensino, foi possível garantir uma aprendizagem de funções contextualizada, utilizando exemplos atualizados e científicos da área. Além disso, beneficiou o professor pesquisador em suas descobertas de novos contextos deste conteúdo e contribuiu para o Ensino da Matemática com um trabalho sobre algumas aplicações do conteúdo de funções nas Ciências Agrárias.

Palavras-chave: Ensino de matemática. Ciências agrárias. Contextualização. Funções matemáticas.

\section{ABSTRACT}

This text aims to share a teaching experience of mathematical functions in the Agrarian Sciences area, through a contextualized classroom practice, in the Agronomy and Zootechny courses of UTFPR (Federal Technological University of Paraná) Campus Dois Vizinhos-Paraná-Brazil. The teaching experience was carried out with 3 (three) groups of Agronomy (2013, 2014 and 2016) and 3 (three) classes of Zootechny (2013, 2014 and 2015). With this teaching experience, it was possible to guarantee a contextualized learning of functions, using up-to-date and scientific examples of the area. In addition, it benefited the researcher professor in his discoveries of new contexts of this content and contributed to the Teaching of Mathematics with a work on some applications of the content of functions in the Agrarian Sciences.

Keywords: Mathematics teaching. Agrarian sciences. Contextualization. Mathematical functions.

\section{INTRODUÇÃO}

Inúmeras dificuldades ainda são encontradas pelos alunos no que tange a aprendizagem em Matemática no Ensino Superior. Malta (2004) ressalta que as preocupações convergem para as disciplinas iniciais dos cursos

1 Universidade Tecnológica Federal do Paraná 
devido ao número crescente de reprovações e que os alunos chegam com retração e dificuldades na disciplinas de Matemática.

Para Clay, et al (2015, p.09), “a falta de habilidades matemáticas avançadas dificulta a capacidade de integrar plenamente as tecnologias da era da informação aos processos de decisão.” Desse modo é necessário que práticas inovadoras sejam criadas pelos professores, a fim de sanar algumas dessas dificuldades. Carbonell (2002) aponta que o desenvolvimento da inovação acontece quando o professor constrói uma relação mais estreita entre: quem ensina, o conteúdo e o aluno e assim exerça sua prática com paixão e compromisso pela docência.

Além disso, o conteúdo precisa ser apresentado com uma relação de utilidade entre a área de graduação do estudante e a disciplina de Matemática, tornando assim o conhecimento relevante. Nesse sentido, é afirmado que:

O conhecimento, extraordinariamente complexo e multidimensional, assenta-se em três grandes pilares: o da informação, que gera conhecimento relevante; o da explicação, que facilita a compreensão do por que das coisas; e o da apropriação subjetiva, que contribui para a formação de um critério de opinião pessoal. (CARBONELL, 2002, p. 51)

Dessa maneira, a informação de quais conteúdos são relevantes nos remete a olhar os ementários das disciplinas de Matemática no Ensino Superior e assegurar que aqueles conceitos são necessários ou não para a formação dos profissionais. A explicação é responsável por facilitar a compreensão dos conceitos matemáticos e quando contextualizadas promovem o entendimento da utilidade, no que tange a sua área de conhecimento. A apropriação do conhecimento promove a interdisciplinaridade que permite ao aluno associar os conceitos matemáticos com conteúdos de outras disciplinas.

Baldoino (2012, p.27) ao refletir sobre a construção do conhecimento no Ensino Superior aponta que é necessário almejar "uma aprendizagem que o auxilie os estudantes a entender e a intervir no mundo, em especial, no ambiente profissional no qual ele pretende atuar".

Neste sentido, entende-se que professor de Matemática do Ensino Superior precisa selecionar conteúdos que contribuam para o ambiente profissional ao que seu aluno irá atuar. Assim, ao permitir que o aluno externalize o seu saber e reflita sobre ele, com o objetivo de apreendê-lo, abre-se um caminho para que o aluno venha a “dizer a sua palavra” sendo sujeito da sua própria vida (FREIRE, 1996, apud, BALDOINO, 2012).

Diante do exposto, este texto objetiva compartilhar as contribuições de uma experiência de ensino de funções matemáticas nas Ciências Agrárias, por meio de uma prática contextualizada em sala de aula, nos cursos de Agronomia e Zootecnia da UTFPR (Universidade Tecnológica Federal do Paraná) Campus Dois Vizinhos.

A pratica de ensino foi embasada, teoricamente, em autores cujas publicações tratavam sobre Matemática e o contexto das Ciências Agrárias e também àqueles que publicaram descrevendo sobre o ato de estudar inovações na prática de ensino, aprendizagem e contextualização da Matemática nos cursos de graduação.

\section{O ESTADO DA ARTE DO ENSINO E APRENDIZAGEM DE MATEMÁTICA NAS CIÊNCIAS AGRÁRIAS}

O Ensino e aprendizagem de Matemática na área de Ciências Agrárias ainda é pouco explorado em pesquisas, é escasso o número de publicações que abordam esta articulação.

Rodrigues (2006) compartilhou uma proposta de recursos e estratégias para aulas de Matemática em cursos de Ciências Agrárias. Para o autor o objetivo foi: 
[...] criar uma seção transversal para ser desenvolvida durante o transcorrer de uma disciplina. Buscando alguns modelos matemáticos ou aplicações concretas da matemática objetivando propiciar uma motivação maior ao aluno, e desta forma desenvolver um tema, um problema ou um assunto de modo mais abrangente a partir das aulas de Matemática. (RODRIGUES, 2006, p.75)

Sendo assim, corroborando com Baldoíno (2012, p.27) “a atuação do professor cria os meios através dos quais o aluno é capaz de vir a se apropriar de uma "aprendizagem duradoura”, uma elaboração personalizada acerca do objeto ensinado, em outras palavras, sua construção".

Diante disso, percebe-se que alguns professores de Matemática que ministram aulas nos cursos da área de Ciências Agrárias se preocupam em mostrar aplicações dos conceitos. Porém, poucas publicações são encontradas com esta temática.

Nesse contexto, foi reimpresso em 2008, um livro de autoria de Rosangela de Fátima Sviercoski (1999). O livro intitulado de "Matemática Aplicada às Ciências Agrárias”, aborda os conteúdos de Função, Derivada, Integral, Função de duas variáveis, Geometria Analítica e Álgebra Linear. O objetivo desse livro foi “apresentar uma Matemática mais próxima da realidade, estimulando a interdisciplinaridade, essencial a um aprendizado eficiente, bem como novas perspectivas de trabalho e pesquisa para os futuros profissionais das Ciências Agrárias (SVIERCOSKI, 2008, p.19)”.

O livro é uma referência básica importante para professores que ministram disciplinas de Matemática nos cursos superiores da área de Ciências Agrárias, mas, por se tratar de uma pesquisa realizada em 1999, apresenta alguns contextos desatualizados. Diante disso, Carbonell (2002) ressalta que é a inovação que permite mudar ao longo do tempo, trazendo novidades, e adequando conteúdos às novas realidades, a fim de criar novas formas de saberes.

Neste mesmo assunto, recentemente foi publicado um livro pelo International Plant Nutrition Institute - EUA, 2012, traduzidoem 2015 pela Escola Superior de Agricultura Luiz de Queroz - Piracicaba-SP (ESALQ-USP-SP). Esse livro intitulado de "Matemática e Cálculos para Agrônomos e Cientistas do Solo", tem por objetivo "ensinar os gestores de recursos naturais e futuros, como: 1) integrar informações de diferentes disciplinas e 2) executar cenários de gestão inovadoras usando a melhor ciência disponível.” (CLAY, et al, 2015, p.09).

Esse livro possui uma metodologia de apresentação dos conteúdos de forma diferente, traz os conceitos da agronomia e da ciência do solo como subtítulos e articula com os cálculos matemáticos utilizados. Além disso, articula os conhecimentos de Química, Física e Estatística. É um livro que apresenta muitos contextos, e se encaixa na descrição de Mello (2004) que descreve didaticamente, três categorias para a contextualização, sendo elas:

- a vida pessoal e quotidiana dos alunos em sua riqueza e complexidade, que inclui de problemas
econômicos a questões de convivência pessoal; de sexualidade a relações com o meio ambiente; do
mundo do trabalho ao mundo da família; da gestão da vida financeira à gestão do corpo e da saúde;

- a sociedade ou mundo em que o aluno vive, também rico e complexo, incluindo toda sorte de temas, questões e problemas numa perspectiva globalizada e unificada pelas tecnologias da comunicação e transmissão de informação: política, economia, desenvolvimento científico, entre muitos outros;

- o próprio ato de descoberta ou produção do conhecimento que pode ser reproduzido ou simulado. (MELLO, 2004, p.4)

Diante disso, é visível que um profissional da área de Ciências Agrárias precisa ser capaz de articular a vida pessoal, o ambiente, a sociedade e a produção do conhecimento, de modo que o conhecimento seja construído com base nas relações estimuladas por múltiplos contextos, com diferentes características (SPINELLI, 2011). "Pois, há uma concepção epistemológica de que o sujeito constrói seu conhecimento quando relaciona diversos significados conceituais uns com os outros, compondo dessa forma uma rede de significados” (SPINELLI, 2011, p.13).

Ainda, nesse parâmetro, ao apresentar as possíveis aproximações entre o ensino de Matemática e o contexto das Ciências Agrárias com aporte à interdisciplinaridade, Pereira e Santos Junior (2015) apontam que as 
aproximações interdisciplinares podem mostrar como o saber matemático contribui para o ensino na área de Ciências Agrárias.“A percepção da ampla aplicação que a Matemática possui se constitui em uma nova metodologia para despertar o interesse dos estudantes” (PEREIRA E SANTOS JUNIOR, 2015, p.07).

Contudo, estas são as publicações científicas as quais se teve acesso até o presente momento. É uma área de estudos escassa e que exige uma atitude interdisciplinar do professor. Logo, em virtude dos poucos estudos encontrados tem-se a motivação para novas pesquisas e novas ações com essa temática surgem.

\section{CAMINHOS METODOLÓGICOS}

A presente pesquisa se classifica como pesquisa-ação educacional, qualitativa de cunho interpretativo. É pesquisa-ação educacional porque para Tripp (2005, p.445), a "pesquisa-ação educacional é principalmente uma estratégia para o desenvolvimento de professores e pesquisadores de modo que eles possam utilizar suas pesquisas para aprimorar seu ensino e, em decorrência o aprendizado de seus alunos". Qualitativa porque "explora as características dos indivíduos e cenários que não podem ser facilmente descritos numericamente” (MOREIRA E CALEFFE, 2008, p.73). O cunho é interpretativo porque relaciona à investigação que ocorre de forma participativa e intensa com a análise dos significados e interpretada por meio de situações do dia a dia no meio social em que a pesquisa está ocorrendo (MOREIRA E CALEFFE, 2008).

Esta ação foi realizada com 3 (três) turmas do $2^{\circ}$ período do curso de Agronomia (2014, 2015 e 2016) na disciplina curricular de Cálculo, e com 3 (três) turmas do $1^{\circ}$ período do curso de Zootecnia (2013, 2014 e 2015) na disciplina curricular de Matemática, ambos os cursos são ofertados na UTFPR (Universidade Tecnológica Federal do Paraná) Campus Dois Vizinhos e possuem nas ementas o conteúdo de funções.

As etapas da ação didática foram:

1. Distribuição por grupos de artigos de revistas científicas da área de Ciências Agrárias;

2. Apresentação dos artigos pelos alunos;

3. Entrega de um relatório com opinião dos grupos sobre a atividade e sobre os artigos estudados;

Este artigo contempla uma das etapas de uma pesquisa de doutorado que visa analisar contribuições de ensino de Matemática na área Ciências Agrárias. A pesquisa encontra-se aprovada no conselho de ética de Seres Humanos da Universidade Tecnológica Federal do Paraná (Parecer: 1.675.433/2016).

\section{$4 \quad$ RESULTADOS E DISCUSSÕES}

Neste tópico serão apresentados os resultados da ação educacional realizada, e as discussões amparadas pelo referencial teórico da pesquisa. Para tanto, essas discussões foram organizadas seguindo as etapas:

$1^{0}$ etapa: Distribuição por grupos de artigos de revistas científicas da área de Ciências Agrárias.

No primeiro momento foi realizada a distribuição de 25 (vinte cinco) artigos de revistas científicas da área de Ciências Agrárias. Esses artigos traziam temáticas dos cursos de Agronomia e Zootecnia, como descritas no quadro 1 a seguir: 


\section{Quadro 1 - Título dos artigos utilizados e as funções matemáticas contextualizadas}

\begin{tabular}{|c|c|}
\hline Título do artigo & Função Matemática Contextualizada \\
\hline $\begin{array}{l}\text { Exigência nutricional de lisina digestível para galinhas poedeiras leves em } \\
\text { produção }\end{array}$ & Função Linear \\
\hline $\begin{array}{l}\text { Desenvolvimento e produtividade de grãos do sorgo de Guiné “Gigante” em } \\
\text { função da época de plantio }\end{array}$ & Função Linear e Função Quadrática \\
\hline Arranjo de plantas e produção de dois híbridos simples de milho & Função Linear e Função Quadrática \\
\hline $\begin{array}{l}\text { Seleção de modelos não-lineares para a descrição das curvas de crescimento } \\
\text { do fruto do cafeeiro }\end{array}$ & Função Exponencial \\
\hline $\begin{array}{l}\text { Área foliar de feijão-vagem (Phaseolusvulgaris L.) em função de dimensões } \\
\text { foliares }\end{array}$ & $\begin{array}{l}\text { Função Linear, Função Quadrática e Função } \\
\text { Exponencial }\end{array}$ \\
\hline $\begin{array}{l}\text { Crescimento do capim Xaraés estabelecido em duas classes de solos e } \\
\text { submetido a doses crescentes de nitrogênio no norte tocantinense }\end{array}$ & Função Linear e Função Quadrática \\
\hline $\begin{array}{l}\text { Seleção de modelos de regressão para estimar a área foliar de macieiras } \\
\text { 'royal gala’ e ‘fuji suprema' sob tela antigranizo e em céu aberto }\end{array}$ & Função Linear e Função Quadrática \\
\hline $\begin{array}{l}\text { Modelagem matemática aplicada ao crescimento de tilápiasem tanques-rede } \\
\text { no submédio do São Francisco }\end{array}$ & Função Exponencial \\
\hline Produtividade de feijão caupi em função da calagem e fósforo & Função Linear e Função Quadrática \\
\hline $\begin{array}{l}\text { Parâmetros físicos do solo relacionados } \\
\text { da frente de molhamento }\end{array}$ & Função Exponencial e Função Logarítmica \\
\hline $\begin{array}{l}\text { Previsão do número de frutos a partir da quantidade de estruturas } \\
\text { reprodutivas em laranjeiras }\end{array}$ & Função Exponencial \\
\hline $\begin{array}{l}\text { Desempenho de cultivares de girassol sob diferentes lâminas de irrigação no } \\
\text { Vale do Curu, CE }\end{array}$ & Função Linear e Função Quadrática \\
\hline $\begin{array}{l}\text { Contribuição da estrutura interna na perda de carga de filtros de areia } \\
\text { utilizados na irrigação }\end{array}$ & Função Exponencial \\
\hline $\begin{array}{l}\text { Caracterização analítica e geométrica da metodologia geral de determinação } \\
\text { de distribuições de Weibull para o regime eólico e suas aplicações }\end{array}$ & Função Linear e Função Exponencial \\
\hline $\begin{array}{l}\text { Formas de aplicação e doses de nitrogênio em cobertura na cultura do feijão- } \\
\text { Caupi }\end{array}$ & Função Quadrática \\
\hline Eficiência do uso da radiação em cultivos de milho em Alagoas & Função Exponencial \\
\hline $\begin{array}{l}\text { Modelagem da área foliar de duas cultivares de amendoim em função das } \\
\text { dimensões lineares dos folíolos }\end{array}$ & Função Linear \\
\hline $\begin{array}{l}\text { Avanços metodológicos na avaliação de alimentos e de exigências } \\
\text { nutricionais para aves e suínos }\end{array}$ & Função Quadrática \\
\hline Curva de Lactação na Raça Guzerá & $\begin{array}{l}\text { Função Quadrática, Função Exponencial e } \\
\text { Função Logarítmica }\end{array}$ \\
\hline $\begin{array}{l}\text { Valor nutritivo e características fermentativas de silagens de capim-elefante } \\
\text { com adição de casca de café }\end{array}$ & Função Quadrática \\
\hline Curva de crescimento de frangos de corte e suínos & Função Cúbica e Função Quadrática \\
\hline $\begin{array}{l}\text { Parâmetros genéticos de características estimadas da curva de crescimento } \\
\text { de ovinos da raça Santa Inês }\end{array}$ & Função Exponencial \\
\hline Utilização de funções matemáticas no estudo da curva de lactação em caprinos & Função Exponencial e Função Logarítmica \\
\hline $\begin{array}{l}\text { Avaliação econômica da utilização de diferentes níveis de polpa cítrica com } \\
\text { ou sem adição de complexo enzimático nas dietas de suínos }\end{array}$ & Função Linear \\
\hline $\begin{array}{l}\text { Modelos não-lineares para descrever a curva de crescimento de ovinos da } \\
\text { raça Santa Inês no vale do Gurguéia }\end{array}$ & Função Exponencial \\
\hline
\end{tabular}

Fonte: Autoria própria

Os artigos citados no quadro anterior foram publicados entre os anos de 2000 e 2015 em diversas revistas da área Ciências Agrárias. A seleção dos artigos foi realizada pelo professor pesquisador. Ao analisar este quadro é possível quantificar que 44 \% (11 artigos) apresentados pelos alunos contextualizavam a Função Quadrática, 56\% (14 artigos) contextualizavam a Função Linear, 44\% (11 artigos) contextualizavam a Função Exponencial, 12\% (3 artigos) contextualizavam a Função Logarítmica e 4\% (1 artigo) contextualizava a Função Cúbica. Vale 
ressaltar que em um mesmo artigo podem aparecer diversas funções, no caso dos artigos apresentados, havia artigos com até 3 tipos de funções contextualizadas.

Para tanto, essa proposta de aproximar o conteúdo de funções matemáticas com situações reais de experimentos realizados, é para o estudante, futuro profissional "contextualizar o conhecimento no próprio processo de sua produção é criar condições para que ele experimente a curiosidade e o encantamento da descoberta e a satisfação de construir o conhecimento com autonomia (MELLO, 2004, p.6)”.

Contudo, com esta etapa foi possível conhecer diversos contextos de aplicações de funções matemáticas. Para o professor pesquisador esta é uma etapa fundamental para responder as questões do "para que serve" os conteúdos de Matemática estudados nesses cursos. E ainda, ao elencar as aplicações de funções matemáticas no contexto de outras disciplinas que eles ainda vão estudar futuramente, promove uma habilidade interdisciplinar que capacita esses futuros profissionais a resolver problemas decorrentes de sua área de formação.

$2^{\mathrm{a}}$ etapa - Apresentação dos artigos pelos alunos

Na etapa seguinte, os acadêmicos em grupo (de 3 a 5 pessoas) fizeram a leitura dos artigos e apresentaram em slides para os colegas, em um tempo de até 20 minutos. Na apresentação eles precisavam mostrar os seguintes pontos fundamentais:

- Título do artigo

- Objetivo do artigo

- Metodologia da pesquisa

- Funções matemáticas encontradas no artigo

- Utilidade da função matemática e sua relação com o objetivo do artigo

- Conclusão

Nesta etapa da apresentação foi possível observar que os alunos apresentavam dificuldades com os termos técnicos e com os termos estatísticos que apareciam no artigo. É factível considerar que no geral, os estudantes conseguiram identificar os tipos de funções apresentadas e sua relação com o contexto. Além disso, também se considera que eles identificaram com sucesso as partes fundamentais do artigo (objetivo, método, resultados, discussões e conclusão).

Para (CLAY, et al, 2015), o futuro profissional deve compreender um método científico; compreender como as experiências são conduzidas e analisadas e desenvolver e testar modelos conceituais e matemáticos.

Diante disso, esta prática com os estudantes foi relevante e enriquecedora, pois, no contexto das Ciências Agrárias é essencial "incentivar seus alunos a lerem e vivenciarem aplicações da Matemática por profissionais da área em que estão estudando, discutir com eles o que foi feito e, quando perceber interesse, propor que façam pesquisas (bibliográficas, na Internet, com outros profissionais) para aprofundar o tema envolvido no estudo (RODRIGUES, 2006, p.75)”.

Logo, a contextualização é algo fundamental para a formação do profissional de Ciências Agrárias, pois proporciona ao aprendiz articular os conceitos a um raciocínio crítico sobre o conteúdo estudado. Já ao professor, cabe executar a pratica docente contextualizada, uma vez que esta alicerça o trabalho efetivamente interdisciplinar na qual a criação de contexto pode promover a interdisciplinaridade.

Nesta mesma perspectiva, Paulo Freire (2004) ao descrever sobre o ato de estudar descreve que: 
Estudar seriamente um texto é estudar o estudo de quem, estudando, o escreveu. É perceber o condicionamento histórico-sociológico do conhecimento. É buscar as relações entre o conteúdo em estudo e outras dimensões do conhecimento. Estudar é uma forma de uma forma de reinventar, de recriar, de reescrever - tarefa de sujeito e não de objeto. Desta maneira, não é possível a quem estuda, numa tal perspectiva, alienar-se ao texto, renunciando assim à sua atitude crítica em face dele. (FREIRE, 2004, p. 01)

Desta forma, o estudo de textos em disciplinas da área de Matemática no Ensino Superior promove relações entre conteúdo e área de formação acadêmica numa outra dimensão do conhecimento, ou seja, enxergar a presença do conhecimento matemático em um texto da área Ciências Agrárias.

$3^{\circ}$ etapa: Entrega de um relatório com opinião dos grupos sobre a atividade e os artigos estudados.

Para finalizar a atividade de contextualização de funções foi proposto aos estudantes que entregassem por escrito um relatório com informações e opiniões sobre a atividade em questão.

A Questão 1 e 2, erade cunho informativo e identificador, na qual o grupo colocava o título do artigo e o objetivo. Nessa questão, todos os grupos apontaram corretamente o título e o objetivo do artigo.

Na questão 3 que tratava da identificação dos tipos de funções matemáticas que estavam representadas no artigo para discutir os dados/experimentos ou ilustrar as discussões dos resultados, ocorreu um percentual de $0,04 \%$ de erros na identificação, o que representa 3 dos 72 grupos que apresentaram nesses 3 anos nos dois cursos. Essa identificação é importante para dar significado ao conhecimento de funções, pois "o aluno precisa ser seduzido para a importância de compreender as tendências [...], e a partir dessa motivação, valorizar a aprendizagem de funções” (MELLO, 2004, p. 10-11).

Ao descrever o que representava as figuras ilustrativas de funções no artigo (questão 4) foi constatado que os 3 (três) grupos não responderam esta questão, no entanto, os grupos restantes conseguiram relacionar o objetivo de cada gráfico apresentado no artigo com a função matemática, e assim, puderam perceber em que contexto era utilizado cada tipo de função.

Na questão 5, o grupo precisava responder se considerava que foi necessário o uso de representações de funções matemáticas, para explicar e discutir os resultados. $92 \%$ responderam que sim e $8 \%$ responderam que não. Nesse sentido é importante que o aluno perceba o significado a partir dos contextos e compreenda a relevância e aplicabilidade do conhecimento para entender fatos, tendências, fenômenos e processos (MELLO, 2004).

Na questão seguinte (6) foi proposto que os grupos assinalassem as principais dificuldades encontradas na leitura do artigo. A tabela 1, mostra como ficou o resultado dessa questão.

Tabela 1 - Dificuldades encontradas pelos alunos dos cursos de Agronomia e Zootecnia da UTFPR ao ler os artigos científicos.

\begin{tabular}{cc}
\hline Dificuldades encontradas ao ler o artigo & Quantidade de grupos \\
\hline Não houve & 24 \\
Termos técnicos & 13 \\
Representações de Funções Matemáticas & 30 \\
Termos estatísticos & 15 \\
Forma de escrita & 45 \\
Outros & 0 \\
\hline \multicolumn{2}{c}{ Fonte: dados da pesquisa }
\end{tabular}


Alguns grupos citaram dificuldades em apenas um dos requisitos elencado, enquanto outros grupos apontaram embaraço de entendimento em vários requisitos. Percebe-se que a forma de escrita foi a principal delas, seguida da identificação e interpretação de funções matemáticas. Esse fato nos remete a pensar sobre a leitura de textos no ensino superior, pois, a leitura se constitui um fator fundamental para a formação do profissional.

Freire (2004) propõe que toda a prescrição de leitura de estudo de um texto deve refletir "uma intenção fundamental de quem a elabora: a de atender ou a de despertar o desejo de aprofundar conhecimentos naqueles ou naquelas a quem é proposta” (FREIRE, 2004, p.01). Caso contrário, os leitores para os quais a leitura foi indicada não serão motivados.

É diante deste contexto que a importância da leitura de um texto científico da área pertinente a graduação, com o objetivo de motivar o estudo de funções matemáticas, mesmo que ainda nos primeiros períodos do curso, é uma prática inovadora capaz de trazer contribuições para os estudantes.

Na sequência, os estudantes relataram a conclusão do grupo sobre o tema do "artigo" e sua relação com a Matemática (questão 7), essa foi a questão mais gratificante do trabalho, pois, mostrou como os acadêmicos interpretaram a atividade proposta. Sendo assim, a atividade diferenciada permitiu transpor a barreira rígida escolar para construir conhecimentos condizentes com uma determinada localidade (CARBONELL, 2002). Os acadêmicos relataram que gostaram da atividade, porque mostrava em que situações eles usam ou usariam Matemática em seu curso de graduação.

Ao analisar os 72 comentários, foi possível observar que os acadêmicos perceberam a importância da Matemática nos contextos. Com isso, mesmo que ainda distante de fazerem trabalhos de experimentação a campo ou em laboratórios, percebem que vão precisar de alguns conceitos matemáticos para explicar os resultados. Sviercoski (2008, p.19), acredita que os estudantes “certamente se confrontarão com a necessidade crescente de formulações quantitativas e modelos, fatores imprescindíveis à efetiva implementação de uma Agricultura de Precisão".

E na última questão os grupos opinaram sobre a atividade proposta, a tabela 2 mostra esses resultados.

\section{Tabela 2 - Opinião dos alunos dos cursos de Agronomia e Zootecnia da UTFPR sobre a atividade proposta}

\begin{tabular}{cc}
\hline Opinião sobre a atividade proposta & Quantidade de grupos \\
\hline Ótimo & 18 \\
Bom & 34 \\
Regular & 20 \\
Ruim & 0 \\
Total & 72 \\
\hline
\end{tabular}

Fonte: dados da pesquisa

Esta última questão remete a uma avaliação da proposta e do professor. A atitude inovadora de colocar uma apresentação de trabalho em uma disciplina de Matemática, no início assustou os acadêmicos, pois, estão acostumados com listas extensas de cálculos mecânicos. Nesse sentido, Pereira e Santo Junior (2015, p.07) descrevem que "no ensino de Matemática novas fontes de conhecimento são geradas no diálogo com contextos de suas aplicações, criando assim, uma rede de significados para os conceitos ditos abstratos e sem utilidade".

Para Baldoíno (2012), alcançar a tão almejada “aprendizagem com significado” no contexto universitário, exige do professor habilidades de comunicação. A forma de apresentar o objeto de ensino precisa estarmunida de "sedução pedagógica". 
Esta atividade foi uma maneira que o professor pesquisador encontrou para "seduzir" os alunos a conhecerem algumas aplicações dos conteúdos de Matemática, e ainda, mostrar como o conhecimento científico é construído com o uso de conceitos matemáticos em pesquisas científicas.

\section{CONSIDERAÇÕES FINAIS}

Esta experiência de ensino de funções matemáticas na área Ciências Agrárias, por meio de uma prática contextualizada em sala de aula, trouxe contribuições para os acadêmicos dos cursos de Agronomia e Zootecnia, beneficiou o professor pesquisador com descobertas de contextos e contribuiu para o Ensino da Matemática com um trabalho sobre algumas aplicações do conteúdo de funções nas Ciências Agrárias.

Para os estudantes, além, de ter sido uma prática inovadora, que propiciou um pequeno distanciamento de listas extensas de exercícios de cálculos mecânicos, promoveu aprendizagem com significados, os motivou a estudar a disciplina sabendo um pouco de sua utilidade e os ajudou a refletir que as soluções para muitos problemas requerem a capacidade de integrar informações utilizando a Matemática com base científica. E ainda, é notório que a ação propiciou aos estudantes, mesmo que nos primeiros períodos do curso, o contato com artigos científicos de diversas temáticas que farão parte do seu currículo nos próximos semestres.

Para o professor pesquisador, foi um momento de grande descoberta de contextos de inserção da Matemática nas Ciências Agrárias, se aproximando do contexto de estudo dos cursos de Agronomia e Zootecnia. Assim, o professor ao se deparar com as recorrentes perguntas do "para que serve?” estará munido de argumentos válidos e de contextualizações que não fujam à realidade.

No âmbito do Ensino de Matemática, práticas inovadoras que dão certo, produzem conhecimento e geram aprendizagem, precisam ser compartilhadas, para que outros profissionais tenham acesso a alguns temas de aplicações de Matemática nas Ciências Agrárias e sintam-se motivados a buscar na contextualização a motivação para ensinar Matemática.

Contudo, esta atividade é apenas o ponto de partida para uma extensa pesquisa que articula o Ensino de Matemática e o contexto da área Ciências Agrárias. 


\section{REFERÊNCIAS}

BALDOÍNO, Eduardo F. Ensinar e Aprender na Educação Superior: Possibilidades de Uma Prática Progressista. Revista de Ensino, Educação e Ciências Humanas, Londrina, v. 13, n. 2, p. 25-34, Out. 2012. Disponível em: http://www.pgsskroton.com.br/seer/index.php/ensino/article/view/685. Acesso em: 10 de ago.2016.

CARBONELL, Jaume. A aventura de inovar: mudança na escola. Porto Alegre: Artmed, 2002 (Coleção Inovação pedagógica).

CLAY, David E. CARLSON, C. Gregg CLAY, Sharon A. MURRELL, T.Scott. Matemática e Cálculos para Agrônomos e Cientista do Solo. Piracicaba, SP: International Plant Nutrition Institute, 2015.

FREIRE, Paulo. Considerações em orno do ato de estudar. Revista Espaço Acadêmico, № 33, Fevereiro de 2004. Disponível em: http://www.espacoacademico.com.br/033/33pc_freire.htm. Acesso em: 04 de set. 2015.

MALTA, Iaci. Linguagem, leitura e matemática. IN: CURY, H. N. Disciplinas matemáticas em cursos superiores: reflexões, relatos, propostas. Porto Alegre: EDIPUCRS, 2004. p.41-62.

MELLO, GuiomarN. de. Transposição didática, interdisciplinaridade e contextualização. São Paulo: 2004. Disponível em: http://www.namodemello.com.br/pdf/escritos/outros/contextinterdisc.pdf. Acesso em: 15 de ago. 2015.

MOREIRA, Herivelto; CALEFFE, Luiz G. Metodologia da pesquisa para o professor pesquisador. 2. ed. Rio de Janeiro: Lamparina, 2008.

PEREIRA, Luciana. B. C. SANTOS JUNIOR, Guataçara. O Ensino de Matemática nas Ciências Agrárias: possíveis aproximações interdisciplinares. ANAIS... VII Encontro Mineiro de Educação Matemática. São João Del Rei - Minas Gerais. Disponível em: http://www.ufjf.br/emem/files/2015/10/O-ENSINO-DE-MATEMATICANAS-CI\%C3\%8ANCIAS-AGR\%C3\%81RIAS-POSS\%C3\%8DVEIS-APROXIMA\%C3\%87\%C3\%95ESINTERDISCIPLINARES.pdf. Acesso em 12 de jun.2016.

RODRIGUES, Walter. M. Recursos e estratégias propostas para aulas de matemática em cursos de ciências agrárias. Revista Educação Agrícola Superior. Publicação da Associação Brasileira de Educação Agrícola Superior- ABEAS.Vol. $21 \mathrm{~N}^{\circ} 01$ - 2006. Disponível em: http://www.abeas.com.br/wt/files/16_2006.1.pdf. Acesso em: 23 de jan. 2016.

SPINELLI, Walter. A construção do conhecimento entre o abstrair e o contextualizar: o caso do ensino da Matemática. 2001. Tese de doutorado - Faculdade de Educação, Universidade de São Paulo, São Paulo, 2011. Disponível em: www.teses.usp.br/teses/disponiveis/48/48134/tde...134105/.../WALTER_SPINELLI.pdf. Acesso em: 15 de ago.2015.

SVIERCOSKI, Rosângela. F.Matemática Aplicada a Ciências Agrárias: análise de dados e modelos. $4^{\mathrm{a}}$ reimpr. - Viçosa, MG:UFV, 2008.

TRIPP, David. Pesquisa-ação: uma introdução metodológica. Educação e Pesquisa, São Paulo, v. 31, n. 3, p. 443-466, set./dez. 2005. Disponível em: <http://www.scielo.br/pdf/\%0D/ep/v31n3/a09v31n3.pdf>. Acesso em: 6 jan. 2015. 